\title{
The influences and consequences of being digitally connected and/or disconnected to travellers
}

\author{
Adrian Tanti ${ }^{1} \cdot$ Dimitrios Buhalis ${ }^{1}$
}

Received: 25 April 2016/Revised: 16 February 2017/Accepted: 22 February 2017 /

Published online: 6 March 2017

(C) The Author(s) 2017. This article is published with open access at Springerlink.com

\begin{abstract}
Technological progress and tourism have worked in tandem for many years. Connectivity is the vehicle that drove the goal of technologically enhanced tourism experiences forward. This study, through an exploratory qualitative research identifies the factors that boost and/or distract travellers from obtaining a digitally enhanced tourism experience. Four factors can boost and/or distract travellers from being connected: (1) hardware and software, (2) needs and contexts, (3) openness to usage, and (4) supply and provision of connectivity. The research also analyses the positive and/or negative consequences that arise from being connected or disconnected. A Connected/Disconnected Consequences Model illustrates five forms of positive and/or negative consequences: (1) availability, (2) communication, (3) information obtainability, (4) time consumption, and (5) supporting experiences. A better understanding of the role and consequence of connectivity during the trip can enhance traveller experience.
\end{abstract}

Keywords Connectivity · During-trip stage · Unplugging · Selective unplugging · Social Wi-Fi

This paper is an extended and updated version of a conference paper titled 'Connectivity and the Consequences of Being (Dis)connected' previously published in the proceedings of Information and Communication Technologies in Tourism 2016 Conference (ENTER 2016) held in Bilbao, Spain, February 2-5, 2016.

Dimitrios Buhalis

dbuhalis@bournemouth.ac.uk

Adrian Tanti

i7635916@bournemouth.ac.uk

1 Faculty of Management, Bournemouth University, Bournemouth, Dorset, UK 


\section{Introduction}

The tourism sector is often considered to be an information intense industry (Fotis et al. 2012). Therefore, it is important to understand how technology, together with online connectivity, has fundamentally reshaped the distribution of information (Buhalis and Law 2008) and the way people experience their travel (Neuhofer et al. 2014). For this reason, several researchers and developers have undertaken the challenge to discover or produce a piece of work to fuse technology with tourist experiences (e.g. Wang et al. 2012; Berger and Paris 2013; Hannam et al. 2014; Neuhofer et al. 2015; Wang et al. 2014; Paris et al. 2015). Connectivity has become such a crucial technological development that innovative projects like Facebook's solar powered drone (see: http://www.internet.org) or Google's balloon powered technology (see: http://www.google.com/loon) are being developed to deliver connectivity even in the most remote areas around the world.

Try and visualise a traveller who is about to embark on a journey. As he makes his way to the airport, he listens to music on Spotify, keeps socially updated on Facebook, and completes the online check-in for the flight. He boards the flight with a boarding pass that was retrieved on a smartwatch, arrives at the destination, and books a ride with Uber to the city centre. After checking-in at the hotel, the visitor selects and books a restaurant through TripAdvisor, and then navigates to it using Google Maps. Once the food arrives, he captures a photo and uploads it on Instagram and Facebook, shares his location and writes a short insight on Twitter, chats on WhatsApp and reviews the restaurant on TripAdvisor. Google Now, suggests a list of attractions in the vicinity that he might want to visit. Once in the recommended attraction, he opens Periscope and shares a live stream of the view with people from all around the world. Current technology allow for all these activities to be performed effectively and efficiently. Although this, by no means, represents how all travellers use technology, it illustrates functional possibilities that users can potentially operate.

The ever-increasing body of work on how information and communication technologies (ICTs) influence travellers during their trip has often focused on how digital media, software, and devices can increase communication, gather information, co-create, and improve experiences (e.g. Buhalis and Amaranggana 2013; Buhalis and Foerste 2013, 2015; Wang and Fesenmaier 2013; Lamsfus et al. 2015). On the opposite end of the spectrum, there is also emerging research on the induced experiences and tensions resulting from disconnection or unplugging from technology (e.g. Pearce and Gretzel 2012; Paris et al. 2015; Germann Molz and Paris 2015).

This study aims to explore the factors that boost or distract the use of connectivity during a trip and the subsequent positive and/or negative consequences of being connected and/or disconnected. The outcomes of these findings offer strategic implications for tourism marketers, and a different perspective for researchers. 


\section{Literature review}

\subsection{Online content and tourism experiences}

The accumulation of information and online content shapes the tourism experience in three different stages: pre-trip, during-trip, and post-trip (Hjalager and Jensen 2012). The events that occur before the trip (e.g. planning), during (e.g. at destination) and after the trip (e.g. recollection) make up one's individual subjective evaluation and undergoing of a travel experience (Tung and Ritchie 2011). During the planning process, tourists use information search to obtain ideas, seek for alternatives, and help avoid places that does not interest them (Xiang and Gretzel 2010). Through reading online reviews, travellers gain a clearer picture of what to expect, increase their confidence in decision making and reduce the risk of satisfaction disconfirmation (Xiang and Gretzel 2010; Jun et al. 2012). At the posttrip stage travellers socialise, communicate, share experiences, help others, and reconstruct their memories of the trip by using social media (Jun et al. 2012; Wu and Pearce 2016). In doing so, travellers enter a mental imagery process that has the potential to modify their satisfaction level of their previous trip (Jun et al. 2012).

\subsection{Connectivity and technology enhanced experiences}

Online communication is increasingly challenging the traditional view where tourists manage to disconnect themselves from their home and move into a potentially rewarding, life-changing or challenging space (Pearce 2011). This notion of movement between two distant worlds has been substituted with the idea of 'digital elasticity' (Pearce 2011). Contemporary travellers explore the identity and the world of others while remaining electronically connected with their home world (Pearce and Gretzel 2012). The idea of disconnection whilst travelling has given way to the contemporary travellers' world where they paradoxically make systematic efforts to keep in touch with friends and family (White and White 2007). Constant connectivity enhances the sense of obligation for travellers to retain the same level of presence, attention, and intimacy with their friends and relatives (Pearce and Gretzel 2012; Germann Molz and Paris 2015). As a result of increased use of technology, tasks which were previously fulfilled in the pre-trip and post-trip stages are now being fulfilled during the consumption stage (Wang and Fesenmaier 2013; Wang et al. 2014). The pre-consumption stage has been shortened as travellers tend to plan less and thus become less rigid and more spontaneous. Travellers are more open to change when an activity becomes unsatisfactory and plan alternatives on the spot. The post-trip consumption has become less necessary since experiences are already being shared live on social networks during the consumption stage (Wang et al. 2014; Tussyadiah 2014).

Memorable travel experiences increase the likelihood and the variety of content that travellers are willing to publish on social media (Minazzi and Mauri 2015). As social posts start to become a new form of postcards, the reaction of other users to the content uploaded can shape the travel experience of the uploader. Indeed, Kim 
et al.'s (2013) research shows a significant relationship between social-media enabled communication and emotion. Travellers arguably have a more enjoyable and memorable experience if they acquire positive emotional support and encouragement on social media during their trip.

In addition to social interaction, connected travellers can also shape their experiences through co-creation with service providers. Neuhofer et al. (2014) through the 'experience hierarchy matrix' argue that different levels of utilisation of technology create different degrees of impact on the tourist experience. At the lower level of the matrix, where use of technology is scarce, travellers have no option but to interact or get involved in creating their experiences. Conversely, higher up in the matrix, travellers co-create their experiences with service providers, the tourist consumer and other consumers. At the peak of the matrix, technology becomes a catalyst and an integral part of the travel experience rather than being merely a supporting tool.

If technology-empowered experiences through co-creation is the goal (Neuhofer et al. 2014), then connectivity is the vehicle that can drive this goal forward. Other enablers of technology enhanced experiences, such as hardware and software (Neuhofer et al. 2015), often depend on connectivity to fully maximise their functionalities. The internet allows users to obtain information, share experiences through content and communication, and co-create experiences (Wang et al. 2014; Minazzi and Mauri 2015; Neuhofer et al. 2015). Whereas ubiquitous and reliable $3 \mathrm{G} / 4 \mathrm{G}$ networks are amongst the most widely adopted solutions for connectivity, they are expensive when used abroad. As a result, Wi-Fi, even with its limitations (i.e. lack of coverage), is often the preferred method of connection (Gass and Diot 2010). Wi-Fi can provide intermittent high bursts of data retrieval at a low or free cost, while roaming offers continuous connectivity with low data rates and relatively high costs (Gass and Diot 2010).

Increasingly, the provision of free $\mathrm{Wi}-\mathrm{Fi}$ is being integrated with social logins (see http://www.fusionwifi.com; http://www.purplewifi.net). Through social logins users manage account registrations and passwords more efficiently and reduce the burden of "password fatigue" where users need to manage multiple accounts across different websites and/or services. This service, termed as Social Wi-Fi, provides users with the ability to seamlessly gain access to connectivity, and also provides valuable social data for organisations. At the same time, mining of personal data also raises privacy and security issues (Bonneau et al. 2009; Wang et al. 2012; Gafni and Nissim 2014). Third party applications are able to gain access to data which is already available on the user's profile: access to basic information (e.g. user name or email address), personal information (e.g. gender, nationality, residence, friend list), created content (e.g. images, videos, status updates), data from potentially nonconsenting users (e.g. friends), and the writing permissions for RPs to share content on the users' social network (Vapen et al. 2015). Nonetheless, users' concerns about loss of privacy and security vulnerability of social logins are often a consequence of poor understanding of how the system works (Gafni and Nissim 2014). While there is increasing literature on social logins (e.g. Sun et al. 2013; Vapen et al. 2015), there is a significant lack of research on Social Wi-Fi, and especially travellers' perception of this connectivity enabler. 


\subsection{Disconnection and unplugging}

The inability to connect online can be either one's own personal decision, or a result of inadequate infrastructure (Paris et al. 2015).The absence of highly familiar sensory inputs and disconnection creates technology-induced tensions to some (Pearce and Gretzel 2012) but a relief for others (Germann Molz and Paris 2015). Pearce and Gretzel (2012) established four types of technology-induced tensions in dead zones areas: (1) social communication tension, (2) work communication tension, (3) security escape tension, and (4) immediacy connectedness tension. Technological dead zones create 'social communication tension' as travellers are unable to meet the typical social expectation to be continuously connected and in constant communication. At the same time, dead zone areas give the traveller a break from this continuous need to be online. The fact that one cannot receive or send communication in dead zone areas offers a good justification for the lack of virtual interaction.

While dead zone areas might create work anxiety, at the same time this disconnection provides a relief from responsibilities as it creates a compelling excuse to not pay attention to work communication. The inability to for travellers to report their well-being to others provokes a security tension to some. On the other hand, being disconnected arouses a sense of adventure, spontaneity, and freedom to truly escape from society. Technological dead zones encourage travellers to focus on the moment and to stimulate skills that technology might typically replace. Pearce and Gretzel (2012) argue that the need to find one's own entertainment and immediate presence in unplugged areas were challenging to some but also rewarding to others.

Induced anxiety from disconnection might be related to the perceived need of staying online, as well as the level of addiction to the internet (Paris et al. 2015). The constant need to check and think about new notifications is often a consequence of smart devices (Harwood 2014). While it is hard to argue against the convenience that internet brings to modern life, a high proportion of the population have developed an addiction to it (Ko et al. 2005). Addicted users might not only feel higher anxiety or distress than typical travellers because of disconnection, but they might also find their denied mobility as unacceptable (Hannam et al. 2014).

Ultimately, the level of reaction towards being unplugged depends on the original intent of the trip, the perceived need of staying connected and the level of control and choice over the disconnection (Paris et al. 2015). In practice, Paris et al. (2015) argue that there might be marketing potential for disconnection as long as it is the travellers' choice to be unplugged. If the traveller is originally aware that he/she will be in a dead zone area, or desire to be in a dead zone area, then the level of anxiety will drop because of the awareness and the preparation which is done beforehand to deal with the eventual disconnection. Arguably, while networking technologies create ways of being virtually together, it also creates new desires for distance and new ways of disconnecting (Germann Molz and Paris 2015). Indeed, Dickinson et al.'s (2016) study on travellers staying in campsites shows that tourists are not constantly connected, and up to 50 percent of them have some desire to disconnect. 


\section{Methodology}

The nature of the study involves issues that need to be explored profoundly. For this reason, an exploratory qualitative research was carried out by conducting face-toface semi-structured interviews. The primary research utilised a purposive sample since it represents an effective method for a pre-determined criteria for the selection of participants (Bryman 2008).

Before conducting the interviews, careful consideration was taken in relation to setting and developing the questions. The questions were kept concise and under one sentence with the aim to be unambiguous and focused. Moreover, the questions were worded to be understood easily by using everyday language. The predetermined questions which were implemented to guide the interview can be observed in Table 1. The interview started with more general questions to ease participants gently into the interview and then moved to more specific topics.

This study required participants who have an affinity for engagement with technology, connectivity and travelling and thus can be termed as 'informal experts' because of their experiences (Line et al. 2011). The term 'informal experts' does not relate to expertise and formal knowledge from a professional point of view, but rather, it focuses on personal interest and the interviewees' good grasp of the range of functionalities of online connectivity and mobility devices (Line et al. 2011). Respondents who have formerly used the internet and technology during their tourist experience had to be identified, as only these users were capable to describe such experiences (Neuhofer et al. 2015). Therefore, the pre-defined criteria consisted of two main factors: first, the informant must be a technology-savvy user who owns a smartphone and is regularly active on the internet and social media. Second, the respondent must have travelled within the last twelve months in order to be able to share his/her related experiences.

The sixteen participants who accepted to participate in the study were interviewed between 26th of May and 8th of June 2015. Three pilot interviews were conducted in the UK prior to executing the final interviews in Malta to minimise ambiguities and confusions in the research. The participants of the pilot interview were asked to be as critical as possible and outline any questions which

Table 1 Pre-determined set of questions to guide the interview

1. How much value do you place on social media and internet in your life?

2. How reliant on connectivity are you during your trip?

3. What are the activities for which you opt to use connectivity during your trip?

4. Can you list an experience where you desired or required to be online but it was not available?

5. Can you list experiences where you desired or required connectivity and it was available?

6. If any, what are the main positives of being connected on your tourist experiences?

7. If any, what are the main negatives of being connected on your tourist experiences?

8. What is your attitude or feeling towards Wi-Fi services that use social logins?

9. How would your holiday have been different if you had no connectivity at all? 
seemed ambiguous or not understandable. As a result, some of the pre-defined questions had to be redeveloped to be clearer for the interviewees.

The island of Malta was selected as an ideal location to obtain experiences of international travellers. Both locals and tourists, when travelling, have to travel beyond their immediate boundaries to access or leave the country, and thus face international enablers and barriers of connectivity. Respondents were recruited through social networks, and verbal advertising. The duration of the interviews ranged between 15 to $52 \mathrm{~min}$. Table 2 shows the sample profile of the respondents. Although the participants may seem socio-demographically diverse, the study was not attempting to recruit a representative sample or claiming for generalisability, but to explore the issue of connectivity in a way which is transferable to related studies (Line et al. 2011).

To safeguard the credibility of the findings and interpretations, rigorous and prolonged engagement with the data was conducted through a qualitative thematic approach. This researchers utilised Braun and Clarke's (2006) six phase guide for thematic analysis. In the first phase, familiarisation with data involved transcription of text from the interviews. This phase also included continuous reading and rereading of the transcriptions to form the initial analysis of the data. In the second phase, initial codes were generated to gain a deeper understanding of the data collected. Descriptive coding was conducted on QSR NVivo 10. The third phase included the search for themes by identifying codes that were related to each other. The fourth phase of the analysis consisted of a review of the themes. To ensure raw data was accurately supported and represented in these themes, the data was interpreted again. In the fifth phase, themes were defined and named, while ensuring

Table 2 Sample profile

\begin{tabular}{lllll}
\hline Number & Pseudonym & Gender & Nationality & Age \\
\hline 1 & Tom & Male & Greek & $20-29$ \\
2 & Mary & Female & Maltese & $20-29$ \\
3 & George & Male & Australian & $40+$ \\
4 & Kate & Female & Italian & $20-29$ \\
5 & Jack & Male & Thailand & $30-39$ \\
6 & Sarah & Female & Italian & $20-29$ \\
7 & John & Male & Maltese & $30-39$ \\
8 & Jessica & Female & Chinese & $30-39$ \\
9 & Michael & Male & Taiwanese & $20-29$ \\
10 & Emily & Female & Italian & $20-29$ \\
11 & James & Male & Maltese & $20-29$ \\
12 & Joanne & Female & German & $30-39$ \\
13 & Ryan & Male & Maltese & $20-29$ \\
14 & Victoria & Female & French & $20-29$ \\
15 & Owen & Male & Maltese & $20-29$ \\
16 & Samantha & Female & Austrian & $20-29$ \\
\hline & & & &
\end{tabular}


that they do not become too diverse or too complex. The sixth and final phase involved the first analysis and write-up of the report.

\section{Findings}

\subsection{Factors influencing a connectivity enhanced experience}

This study has identified both technological and non-technological reasons that influenced the participants' need for connectivity while travelling. The accumulation of these factors has been classified in four main factors: (1) hardware and software, (2) needs and contexts, (3) openness to usage and (4) supply and provision of connectivity. Each of these four main factors has underlying features that can boost or discourage internet enhanced experiences (Fig. 1).

\subsubsection{Hardware and software}

The combination of hardware and software enables connectivity to become, to a certain extent, tangible for users. It is the use of devices and their complimentary software that allow users to connect to the internet and make use of its resources.

\begin{tabular}{|c|c|c|}
\hline $\begin{aligned} \text { Devices } & = \\
\text { Applications } & =\end{aligned}$ & Hardware and Software & $\begin{array}{l}=\text { Deficiencies of technology } \\
=\text { Offline Applications }\end{array}$ \\
\hline $\begin{array}{r}\text { Solo Traveller = } \\
\text { Unfamiliarity }= \\
\text { Purpose of Travel }= \\
\text { (e.g. Discovering) }\end{array}$ & Needs and Contexts & $\begin{array}{l}=\text { Accompanied Traveller } \\
=\text { Familiarity } \\
=\text { Purpose of Travel } \\
\text { (e.g. Relaxation) }\end{array}$ \\
\hline Actively Connected = & Openness to Usage & $\begin{array}{l}=\text { Selective Unplugging } \\
=\text { Self-Imposed total } \\
\text { disconnection }\end{array}$ \\
\hline $\begin{array}{r}\text { Available Infrastructure }= \\
\text { Social Wi-Fi }=\end{array}$ & $\begin{array}{l}\text { Supply and Provision of } \\
\text { Connectivity }\end{array}$ & $\begin{array}{l}=\text { Unavailable Infrastructure } \\
=\text { Lack of knowledge/trust on } \\
\text { foreign service providers }\end{array}$ \\
\hline
\end{tabular}

Fig. 1 Factors that boost or discourage use of connectivity 
The respondents used mobility devices to gain connectivity, and operated a plethora of different software to increase the functionalities of their devices. The speed at which information can be retrieved heavily influences the level of interest in using connectivity to enhance an experience. Modern technology has enabled users to instantly connect online to find information, co-create experiences with friends, relatives and/or suppliers, and consequently become an accompaniment to their trip.

"I use my mobile phone pretty much every time, so first thing in the morning and the last thing I use at night. I get quite fidgety when I'm out and it's not working. (...) I use Facebook-I need to keep in touch with my world. Google Maps, TripAdvisor if I need to find a restaurant or museum and want to make sure that the place I go is well rated. For transport, bus schedules, train schedules" (Victoria).

While hardware and software enable users to connect online, some of their technological deficiencies can at the same time prove to be a barrier for connectivity. As Neuhofer et al. (2015) similarly discovered, deficiencies of technology for the participants included: short battery life, slow and non-intuitive applications or devices. Furthermore, offline applications were perceived to become increasingly more available, and thus reduced the need for the travellers to find connection. Nonetheless, few applications are able to perform all of their functionalities while offline and users typically need to download content prior to utilising them in a destination.

"If you have Wi-Fi you can always do something, unless your mobile dies without battery" (James).

\subsubsection{Needs and contexts}

Different desires and contexts produce different non-technological factors that can either increase or distract the need for users to have a connectivity enhanced experience. This study highlights three types of contexts that have influenced the need for connectivity for the respondents of this study: (1) solo-accompanied travel, (2) familiarity-unfamiliarity of the destination, and (3) purpose of trip. Effectively the impact of these influences on the use of connectivity will depend on the traveller's personal characteristics, interests, culture and previous experiences.

(1) Solo-accompanied travel: Respondents discussed how travelling alone or with the company of others influenced the level of dependency on the internet and the way they used it. Solo travellers often relied on connectivity to assist them in their travels. The ability to connect online became a source of relief for those who were travelling alone:

"I will need internet if I am travelling alone for example because I am quite afraid when I am travelling so I might need the help of the internet to find my way through stations" (John).

Conversely, accompanied travellers obtained this sense of relief through the collective presence of a group of people. Indeed, respondents who travelled with 
friends and/or family did not need connectivity to feel safer since they were either dependent on other people or felt less stressed because they were not alone. Similarly, some maintained that travelling with a guided tour subsided the need of connectivity-especially when it comes to assistance with navigation and information. Therefore, solo and accompanied travellers value and use connectivity differently because of their different needs and contexts.

(2) Familiarity-unfamiliarity of the destination: Participants report that the level of familiarity with the destination influenced the role of connectivity on a tourist experience. Familiarity includes factors such as: knowledge of spoken language, previous experiences in the destination, and prior preparation. Tacitly, the stronger the participants were equipped with these three factors, the less connectivity they required. Conversely, without this knowledge, the internet became the tool which assisted travellers to enhance their experience in a destination. Through rapid information search and availability of rich content in multiple languages, connectivity becomes a great asset for travellers who need to become increasingly familiar with the destination.

(3) Purpose of trip: Participants often highlighted that the purpose of travel has a significant influence on the level of connectivity required. For instance, participants argued that in 'city breaks' they sought to discover the destination at its utmost and thus relied on the internet to seek reviews, to locate museums and other attractions, to find discounts, and to navigate from one place to another. On the other hand, in the case of a more leisure-focused holiday, participants not only used less internet, but also sometimes hoped that they would find less connectivity. Moreover, the purpose of the travel can also influence the type of online activities performed: different contexts produce different needs from online services. Therefore, one can argue that different trip intentions produce different forms of consumption and level of usage.

\footnotetext{
"Well, I think it's quite important to have Wi-Fi somewhere, but it depends where you are. I think when you are in a city trip for example, it's quite cool when you have Wi-Fi because you can check for restaurants or sights or bus times. I think when I'm away and lying on the beach I don't need it too much" (Samantha);

"For example if the holiday, you aim to go on holiday, on a retreat or just to be away from your everyday life, you would probably need much less connectivity and hope to find much less connectivity there than at other destinations!" (Mary).
}

\subsubsection{Openness to usage}

The level of openness to use connectivity during travelling heavily influences the possibility of internet enhanced experiences. Different participants had different perspectives on the level of escape they wanted from their travels. Connectivity, being such an integral part of everyday life, has become comparable to an essential item in a suitcase to some, but to others it has also become an emotional and behavioural baggage. Those who perceive connectivity as a means to enhance their 
experience or a way to keep some connection to the life they are temporarily leaving, are more likely to practice an internet enhanced experience than those who desire to escape from home-both physically and virtually. The study has observed three particular voluntary approaches to connectivity: (1) actively connected, (2) selective unplugging, and (3) self-imposed total disconnection.

The first approach, actively connected, refers to users who desire to be connected throughout their trip. Participants with this approach generally wished to keep socially updated, keep up with any work developments, co-create their experiences, and find tourist details and reviews about particular places. Some respondents even admitted that, during their travels, they sometimes become even more active than usual on social media. This also supports Minazzi and Mauri's (2015) claim that memorable travel experiences can increase the amount and variety of content that travellers' publish on social media.

"I don't post photos or status normally, but, when I travel well it's the time to brag you know [laughs] so I quite often upload photo, but that's also for my family, I want to share my experience-like real time experience with my family and friends as well" (Jessica).

The second approach to connectivity, selective unplugging, refers to being partially active or inactive. This means that users, rather than being completely disconnected from the internet, are selective in what and/or when they want to disconnect. For instance, the following respondent employs selective unplugging with regards to work e-mails:

"When I am on vacation I normally decide not to see any emails; still I search the internet, check the news, log on my Facebook, Twitter, but not emails—so that at least I don't see what work is coming for me when I return home" (George).

Selective Unplugging can also refer to moments of the day where the user consciously decides to stop using the internet, or to restrict online usage to a certain time of the day:

"When I was in a bar, I was looking at places where we could go, and then I just realised, why not just enjoy the moment and I will look up places before sleeping. You have to be conscious to stop doing that sort of thing, because I do it without wanting to. I'm conscious that sometimes I use it too much" (James);

"In normal life you check your Facebook all the time, even if you don't have any alert you just check if you have any notification, so, that kind of habit you actually bring to your holiday as well, so when I'm in holiday I just think, like okay, let's not check-maybe later when I finish this route, when I finish this museum" (Jessica).

Selective unplugging becomes an increasingly important approach as travellers start to recognise the side effects of being completely connected online. The need for selectively disconnecting from aspects of connectivity stems from a conscious 
effort to stop the overdependence of technology and to enrich the physical and emotional experience in a destination. Nonetheless, as certain functionalities and abilities of connectivity are able to complement travel experience, travellers are still open to be connected at certain moments or for specific features. In this approach, travellers strive to find a balance between connection and disconnection in the type of usage and consumption.

The third approach, self-imposed total disconnection, takes the notion of unplugging to a different level. Here, the user at his/her own will decides to completely block internet connectivity. This is not referring to dead zone areas (Pearce and Gretzel 2012) where the user is unable to connect online because of insufficient infrastructure. On the contrary, it is the traveller's personal choice to avoid internet connection, with the aim or hope to fully escape from technology:

"If I'm travelling, like, around with my backpack then I don't use internet-I don't like (using) it. There is some point in the year where I really need to be disconnected" (Sarah).

Self-imposed total disconnection removes any technological anxieties from the trip experience and enables travellers to fully immerse themselves in the destination. Participants with this approach desired to wander around the destination without the assistance or distractions of connectivity. As a result, travellers feel closer to their new environment and their inner senses. Consequently, this approach to connectivity thoroughly reduces the opportunity for an internet enhanced experience.

\subsubsection{Provision and supply of connectivity}

While participants have different options to connectivity during their trip, the ability to connect online remains under the prerogative of the suppliers of connectivity. Provision and supply of connectivity through suitable telecommunications infrastructure (data networks, Wi-Fi) enables users to be connected (Neuhofer et al. 2015). The cost of connectivity often discourages travellers from obtaining a connectivity-enhanced experience. Preference is often given to free Wi-Fi hotspots-even with their limited coverage. Wi-Fi is typically free-to-access and tends to provide faster and more reliable connection than data networks (Gass and Diot 2010). Participants who used 3G/4G networks during their trips often restricted their usage to essential activities and avoided certain functionalities (e.g. social networking, viewing multimedia) to limit the amount of data downloaded and roaming costs. International mobile information search behaviour is constrained by not only the availability of networks but also the cost of network access (Dewan and Benckendorff 2013). Nevertheless, it is important to note that the demolition of roaming charges in Europe in June 2017 might change future usage behaviour as it will enable travellers to use their data allowance throughout Europe and thus facilitating constant connectivity.

"Yeah I use Wi-Fi wherever it is: the hotel, hostel or restaurant or coffee shop. I am not trying to use the $3 \mathrm{G}$ that I have because it costs money and I don't want to spend money when there is Wi-Fi" (Sarah). 
With the proliferation of social network users and the consumers' increasing requirement for provision of connectivity, it is not surprising that organisations are starting to fuse the two together and offer 'Social Wi-Fi'. The term Social Wi-Fi can be defined as the integration of social logins with the accessibility and provision of Wi-Fi.

The premise behind Social $\mathrm{Wi}-\mathrm{Fi}$ is that it provides a more convenient way to access connectivity. More importantly, through Social Wi-Fi, provision of connectivity no longer remains a service which is valuable solely for consumers, but it also becomes a product which is equally valuable for suppliers. Permitting users to utilise Wi-Fi through logging in their respective social networks allows organisations to increase engagement with customers and to also retrieve valuable data. This service allows organisations to have a rare opportunity to obtain live insights and to co-create experiences with their consumers. Nonetheless, the success of Social Wi-Fi is dependent on the acceptance and usage of consumers. Respondents had mixed attitudes towards using Social Wi-Fi and pointed out different positive and negative aspects for using this service. Social Wi-Fi was praised for being more convenient and faster to connect to and also avoids password fatigue-benefits which are similar to the perceived benefits of social logins on websites (Sun et al. 2013; Gafni and Nissim 2014).

"I think using my social account it is way faster and easier and I don't need to figure out a new password which I'm going to forget in the next few days" (Tom);

"Social Wi-Fi was faster, more reliable and I think it's more user friendly as well because it's just one click and you're done" (Joanne);

"Social Wi-Fi is just easier and faster, you don't have to put your name and email and all you data, you just log in, ok, and you are done" (Emily).

On the other hand, because Social Wi-Fi services retrieve data from their social networks, some users were concerned about the intrusiveness of these services. Privacy invasiveness typically manifests itself through authorisation of data retrieval and writing permissions (Vapen et al. 2015). Privacy concerns on Social Wi-Fi perpetuate over and above the typical social logins concerns because travellers lack knowledge on foreign brands that are providing the Social Wi-Fi service. While locals might trust a particular brand due to its established place in its marketplace, a traveller might not necessarily recognise it.

"Especially abroad, who knows, it could be the most popular service abroad, but to me, I have no knowledge of them, so my leniency to give them my information would be super high not too" (Ryan);

"Yeah, first of all it depends on the organisation and secondly if they would use this information for a good reason. Yeah I think it depends on the situation and the company: Mainly who will use my information?" (Tom).

While users are concerned about their privacy, at the same time, they appreciate the fact that suppliers are able to improve the products and services through the data 
collected. Products and services can be especially altered to optimally meet each customer's need and wants.

“...you just press one button and it's all there for you and there's this whole integrated system that recognises a lot of your habits, somehow, and your behavioural patterns so that can come in handy and it might also provide a lot of unsolicited benefits to the other business" (Mary).

This study identifies four factors that influenced the willingness of the participants to connect to Social Wi-Fi: (1) users' attitude towards privacy, (2) availability of substitutes, (3) perceived value of connectivity, and (4) perceived reputation of supplier. The stronger perceived value of connectivity and reputation of supplier, the more likely participants were willing to connect to Social Wi-Fi. Conversely, the stronger the care for privacy and the availability of substitutes, the less likely were respondents open to use Social Wi-Fi.

\subsection{Consequences of connection and disconnection}

The state of being connected or disconnected imposed a number of positive and negative consequences on the respondents. Figure 2 shows five forms of consequences: (1) availability, (2) communication, (3) information obtainability, (4) time consumption, and (5) supporting experiences. In each of these

\begin{tabular}{|c|c|c|c|c|}
\hline \multicolumn{2}{|c|}{ Connected } & Consequences & \multicolumn{2}{|c|}{ Disconnected } \\
\hline Positive & Negative & & Positive & Negative \\
\hline $\begin{array}{c}\text { Engaged with } \\
\text { home }\end{array}$ & $\begin{array}{l}\text { Creates } \\
\text { expectation to } \\
\text { keep contact }\end{array}$ & Availability & True escape & $\begin{array}{l}\text { Disengaged } \\
\text { from home }\end{array}$ \\
\hline $\begin{array}{c}\text { High online } \\
\text { presence }\end{array}$ & $\begin{array}{c}\text { Offline } \\
\text { Unsociability }\end{array}$ & Communication & $\begin{array}{c}\text { Offline } \\
\text { Sociability }\end{array}$ & $\begin{array}{c}\text { Low online } \\
\text { presence }\end{array}$ \\
\hline $\begin{array}{c}\text { Ample } \\
\text { Information }\end{array}$ & $\begin{array}{l}\text { Overload of } \\
\text { information }\end{array}$ & $\begin{array}{l}\text { Information } \\
\text { Obtainability }\end{array}$ & $\begin{array}{l}\text { Unplanned } \\
\text { discoveries }\end{array}$ & $\begin{array}{l}\text { Lack of instant } \\
\text { information }\end{array}$ \\
\hline Efficiency & $\begin{array}{l}\text { Time wasted on } \\
\text { non-holiday } \\
\text { activities }\end{array}$ & $\begin{array}{c}\text { Time } \\
\text { Consumption }\end{array}$ & $\begin{array}{c}\text { Time } \\
\text { exclusively } \\
\text { spent on holiday }\end{array}$ & Inefficiency \\
\hline $\begin{array}{l}\text { Additional } \\
\text { dimension }\end{array}$ & $\begin{array}{l}\text { Excessive } \\
\text { reliance on } \\
\text { connectivity }\end{array}$ & $\begin{array}{l}\text { Supporting } \\
\text { Experiences }\end{array}$ & $\begin{array}{l}\text { Personal skill } \\
\text { development }\end{array}$ & $\begin{array}{c}\text { Missed } \\
\text { Opportunities }\end{array}$ \\
\hline
\end{tabular}

Fig. 2 Representation of the connected/disconnected consequences 
consequences, the research highlights both positive and negative attributes that arise from connection or disconnection.

\subsubsection{Availability}

Availability refers to the presence of the traveller in the online and physical world. The ability to connect online provides travellers an opportunity to maintain connection, intimacy, and movement as they perform social interactions on their devices (Germann Molz and Paris 2015). Being available is important and a relief to some but also a hindrance to others: once connected there is an ever-present expectation to maintain regular contact as if the traveller were still at home. This expectation has also manifested itself in a form of addiction where users constantly keep checking for new notifications. The cognitive and behavioural need to constantly check for notification updates is often linked to smart devices (Harwood 2014). The advantage of being disconnected is that it provided the respondents the chance to truly escape everyday life and immerse in a destination. Whether this escape from connectivity is temporal or throughout the whole course of the trip, it gives travellers the opportunity to leave behind the typical thoughts and challenges of their everyday life and immerse themselves in the travel activity or place. Nonetheless, a degree of contact with "home" was still perceived as important.

"I recall one time when I needed to login to my remote connection at work because something was wrong, and I found a Wi-Fi connection (...) It made me more comfortable knowing that I can control, for example my PC at work, and my mind was at rest that I can access it whenever I want" (John).

“Ten years ago no one expected you to be available. And now when you don't answer a WhatsApp message within some hours, it's like are you alive? So not sure if this is good or bad" (Samantha).

“And I'm going to worry, is my girlfriend going to text me on the chat app or my family going to chat with me and then I disappear, so I'm quite worried that people are going to worry about me. I don't know I'm addicted to social media sometimes" (Jack).

\subsubsection{Communication}

While 'availability' focuses on the presence and accessibility to converse, 'communication' refers to face-to-face or text-based conversations. Online connection provides the ability for travellers to communicate on a number of different platforms. Respondents made use of online services to share texts, images, videos, experiences-either publicly or with friends and relatives. Connectivity allows relationships and networking to grow and flourish rather than stagnate because of temporal distance. The practice of 'digital elasticity' (Pearce 2011; Pearce and Gretzel 2012) was a common feature, as respondents remained electronically connected with their home. One potential disadvantage of connectivity is the risk of neglecting people who are surrounding the traveller during his/her trip. This can 
refer to either the people who are accompanying the traveller, or tour leaders, guides, residents and other travellers. Respondents often admitted that it was far less challenging to get lost on social media than trying to converse with other people on the trip. This potential disadvantage of connectivity becomes the positive consequence of disconnection. Without access to online communications tools, travellers become more sociable and thus interacted through face-to-face conversations. The interaction with accompanied travellers, natives or other travellers can provide the tourist a more immersed experience. Respondents were often disappointed when connectivity managed to replace face-to-face conversations.

"We are always with our mobile phones in our hands, it's annoying, because, people are speaking with people that they are not there, and then when they are with those people, they are speaking to us" (Kate).

"I experienced snow for the first time so I wanted to share it with my boyfriend, so I switched on Skype and I could see his reaction and he could see mine live" (Joanne).

\subsubsection{Information obtainability}

As tourists continue to plan less before travelling to a destination (Wang et al. 2014) and rely on connectivity to find information at the right time and at the right moment, information obtainability becomes increasingly important. One major positive consequence of an internet enhanced experience is the incredible amount of information available (Xiang et al. 2015). Respondents recalled how they used their devices during their travels to obtain assistance with tourist details, navigation, reviews and instant information. However, one negative consequence is that information can be so vast and detailed that at times it can become overwhelming. It also has the ability to take away experiences that are otherwise enjoyed differently. Disconnection provides a compelling reason to wander around a destination and enjoy experiences that are sometimes made redundant by connectivity. Some respondents argued that unplanned discoveries are perhaps even more rewarding than pre-planned activities. Nonetheless, there are occasions where retrieval of information remains essential. The inability to find swift information is one of the main disadvantage of disconnection. Being disconnected provides limited sources and detail of information. Disconnection and unfamiliarity with a destination is a combination that can induce frustration and even cause stressful moments for travellers when information is needed.

"The amount of information that you can get at every moment, every time, in whatever situation. You make the most of the experience, you do not miss anything... While when you don't have internet, you are a bit lost, and you wander around" (Emily).

"Internet makes you plan everything and check in advance, you can even like see the menu of the restaurant, and pick before you go there, and maybe that is not really good for the experiences. (...) Maybe somehow it is even better when there is no connectivity because you can explore yourself. Because when 
you have Wi-Fi you go for what you need, and that's it. Maybe you see more of a place if sometimes you don't have internet" (Samantha).

\subsubsection{Time consumption}

Travellers are often constrained with a limited time during their trips. Connection or disconnection can influence the time consumed on performing certain activities. Connectivity can provide efficiency in information search as it offers access to a large database of information and enable travellers to retrieve information swiftly. Yet, online connectivity can also lead to inefficiency and time wastage when users do not only connect to the internet for holiday purposes but also for non-holiday activities: socialising online, keeping up with work, news and so on (Wang et al. 2014). Travellers can potentially end up spending time on the online world and neglect the opportunity to discover the physical world. The advantage of being disconnected revolves around the idea that time can be exclusively spent on the holiday experience as they are less likely to be distracted if there is no connectivity. At the same time, disconnection can also be time consuming when travellers require retrieval of information. Without the assistance of online content, users have to resort to more traditional, time consuming approaches to seek information.

"I would be walking like I'm a resident there-like I already know what's happening — so that (connectivity) saved me time" (Ryan).

\subsubsection{Supporting experiences}

Online connectivity is able to support users on information, entertainment, and communication requirements. Connectivity provide travellers a sense of security in knowing that any needs can be addressed instantly. Minazzi and Mauri (2015) discussed how tourists reduce the perception of risk through the availability of online information and enrich their experiences with instant decisions using mobility devices. This reduces the conventional stress that arises from temporarily living in a different and unknown environment, often with its different culture, language, norms, especially when visiting for the first time. However, this can also become detrimental when travellers over-depend on it, as connectivity is inconvenient and stressful when it is unavailable. While connectivity has the ability to aid and increase the personal development of travellers, it can also cage the traveller in his/her own online world and miss out on potential learning experiences.

Disconnection can provide travellers with the opportunity to be engaged with the present company and place. Disconnection can stimulate (sometimes dormant) skills and be able to enjoy "...dead zone time, space and immediate companions" (Pearce and Gretzel 2012, p. 12). Nevertheless, respondents felt that lack of connectivity provoked a sense of missed opportunities. Connectivity complements the travel experience as it provides a sense of immediacy and assistance.

"If anything I'd be a bit, not dissatisfied, like be how unfortunate. I'd feel like I missed out on something you know, having internet would have made it a bit 
better the holiday experience. Even though you don't do much, even if you don't post or anything, even just receiving data, it would have complemented the holiday" (Ryan);

"Not necessarily an advantage at time because it might distracts you, however, overall I think it's a plus because it's a service that is available there and you never know what you might need off the internet" (Mary).

Figure 2 illustrates how the five forms of consequences can potentially feature positive and/or negative attributes for both connection and disconnection. The consequences of being (dis)connected depend on the level of control over the decision to have connection or disconnection, the openness for usage and the context of the traveller. The positives from being disconnected are amplified if the disconnection is the traveller's own personal decision through blocking access to connectivity or knowingly travelling in unplugged areas. The negatives will intensify if the disconnection was not a personal decision made by the traveller but was imposed on him/her. The negative consequences of both connection and disconnection can be reduced if the traveller is able (and is allowed to) strike a balance between both approaches. Being connected did not necessarily make the participants unsociable or unable to enjoy the immediate presence or companionship. The respondents' degree of control over the use and duration of connection or disconnection played a huge role in augmenting or decreasing the negative consequences. Selective unplugging was often the respondents' preferred attitude towards connectivity in order to strike a balance between the online and offline world.

\section{Conclusion}

Connection and disconnection have often been studied exclusively in their own respective worlds. In doing so, researchers often ignored the fact that travellers have to commonly adjust between the two states of connections during their travels rather than be completely connected or disconnected. Additionally, the influence of technology has often been observed solely from a software and/or device point of view (e.g. smartphones and wearable technologies) (e.g. Wang and Fesenmaier 2013; Dickinson et al. 2014; Tussyadiah 2014; Wang et al. 2014) but rarely have they specifically concentrated on the main factor that maximises their functionalities: connectivity.

This research aimed to fill this literature gap by understanding the factors that boost or discourage connectivity enhanced experiences and the positive and negative consequences of being connected and/or disconnected. The accumulation of these influences was classified in four main factors: (1) hardware and software, (2) needs and contexts, (3) openness to usage, and (4) supply and provision of connectivity. Travellers' openness to usage is arguably the most influential factor in being connected or disconnected. Without the desire to obtain connectivity all the other factors that can enable internet connection become futile. Conversely, hardware, software, provision of connectivity become crucial supporting tools when 
the user desires to be active online during the trip. Subsequently, the research also presented a number of multifaceted experiential consequences of being connected and/or disconnected. The findings suggest that the consequences of being (dis)connected largely depend on the level of control over the decision to be connected or disconnected, the willingness to use connectivity, the context of the traveller, and the travellers' volitional balance between the two opposite states of connectivity.

The research has identified three different approaches to connectivity. Through the novel approach of focusing on both connection and disconnection, the study introduced the concept of "selective unplugging" where travellers attempt to strike a balance on the usage and dependence on the internet and its supporting tools. Alternatively, travellers might opt to be 'actively connected' throughout their trip, or even practice a 'self-imposed total disconnection'. As a result, businesses seeking to satisfy their customers' needs should attempt to understand the desires of their target markets, and ensure that they are equipped with the appropriate infrastructure. As Paris et al. (2015) also argue, marketing potential exists for both the provision of connection and disconnection. There are numerous examples of organisations and businesses promoting themselves as Wi-Fi friendly, but at the same time, there are also existing places and businesses that promote the fact that they do not provide any connection. One example is Visit Wales' witty marketing campaign whereby they promoted areas of "outstandingly bad mobile reception" (Brand Arcade 2010).

These research present findings from a qualitative exploratory research. Consequently, the results are not generalisable, but they provide a solid foundation for further research. Due to the limitations of the qualitative and purposive sampling approach, a quantitative study can extend this study to test findings on a larger scale. Additionally, future investigations related to this subject may potentially focus on a number of areas, including:

1. the extent to which 'selective unplugging' approach is utilised by travellers,

2. the factors that influence the degree to which 'selective unplugging' approach is used,

3. the role of Social Wi-Fi in the context of travel and tourism.

As technology enhanced experiences, co-creation, and smart destinations continue to emerge and grow (e.g. Buhalis and Amaranggana 2013; Neuhofer et al. 2014, 2015; Buhalis and Foerste 2015), both academics and marketers need to ensure there is appropriate level of infrastructure. Effectively, destinations and organisations need to ensure their telecommunications infrastructure is capable to address the ever expanding needs of the market.

Acknowledgements The research work disclosed in this publication is partially funded by the Master it! Scholarship Scheme (Malta). This Scholarship is part-financed by the European Union-European Social Fund (ESF) under Operational Programme II-Cohesion Policy 2007-2013; "Empowering People for More Jobs and a Better Quality Of Life". 
Open Access This article is distributed under the terms of the Creative Commons Attribution 4.0 International License (http://creativecommons.org/licenses/by/4.0/), which permits unrestricted use, distribution, and reproduction in any medium, provided you give appropriate credit to the original author(s) and the source, provide a link to the Creative Commons license, and indicate if changes were made.

\section{References}

Berger E, Paris C (2013) Exploring the role of Facebook in re-shaping backpacker's social interactions. In: Xiang Z, Tussyadiah I (eds) Information and communication technologies in tourism 2014 [Online]. Springer International Publishing, London, pp 299-312

Bonneau J, Anderson J, Danezis G (2009) Prying data out of a social network [Online]. In: International conference on advances in social network analysis and mining, Athens 20-22 July 2009. IEEE, Washington, pp 249-254. http://ieeexplore.ieee.org/xpl/login.jsp?tp=\&arnumber=5231875\&url= http\%3A\%2F\%2Fieeexplore.ieee.org\%2Fxpls\%2Fabs_all.jsp\%3Farnumber\%3D5231875

Brand Arcade (2010) Visit Wales gets ir right for family vacations. Brand Arcade (Online). 4 June 2010. http://brandarcade.com/?p=657

Braun V, Clarke V (2006) Using thematic analysis in psychology. Qual Res Psychol 3(2):77-101

Bryman A (2008) Social research methods, 3rd edn. Oxford University Press, New York

Buhalis D, Amaranggana A (2013) Smart tourism destinations. In: Xiang Z, Tussyadiah I (eds) Information and communication technologies in tourism 2014. Springer International Publishing, London, pp 553-564

Buhalis D, Foerste M (2013) SoCoMo marketing for travel and tourism. In: Xiang Z, Tussyadiah I (eds) Information and communication technologies in tourism 2014. Springer International publishing, London, pp 175-185

Buhalis D, Foerste M (2015) SoCoMo marketing for travel and tourism: empowering co-creation of value. J Destin Mark Manag 4:151-161

Buhalis D, Law R (2008) Progress in information technology and tourism management: 20 years on and 10 years after the Internet-the state of eTourism research. Tour Manag (Online) 29(4):609-623

Dewan I, Benckendorff P (2013) Impact of Tech Savviness and impulsiveness on the mobile information search behaviour of young travellers. In: Cantoni L, Xiang Z (eds) Information and communications technologies in tourism 2013 (Online). Springer, London

Dickinson JE, Ghali K, Cherrett T, Speed C, Davies N, Norgate S (2014) Tourism and the smartphone app: capabilities, emerging practice and scope in the travel domain. Curr Issues Tour (Online) 17(1): $1-18$

Dickinson JE, Hibbert JF, Filimonau V (2016) Mobile technology and the tourist experience: (dis)connection at the campsite. Tour Manag 57:193-201

Fotis J, Buhalis D, Rossides N (2012) Social media use and impact during the holiday travel planning process. In: Fuchs M, Ricci F, Cantoni L (eds) Information and communication technologies in tourism 2012 (Online). Springer, London, pp 13-24

Gafni R, Nissim D (2014) To social login or not login? Exploring factors affecting the decision. Issues Inf Sci Inf Technol 11:57-72

Gass R, Diot C (2010) An experimental performance comparison of 3G and Wi-Fi. In: Krishnamurthy A, Plattner B (eds) Passive and active measurement springer passive and active measurement. Springer International Publishing, London, pp 71-80

Germann Molz J, Paris CM (2015) The social affordances of flashpacking: exploring the mobility nexus of travel and communication. Mobilities (Online) 10(2):173-192

Hannam K, Butler G, Paris CM (2014) Developments and key issues in tourism mobilities. Ann Tour Res 44(1):171-185

Harwood J (2014) Constantly connected - the effects of smart-devices on mental health. Comput Hum Behav 34:267-272

Hjalager AM, Jensen J (2012) A typology of travellers based on their propensity to go online before, during and after the trip. In: Fuchs M, Ricci F, Cantoni L (eds) Information and communication technologies in tourism 2012 (Online). Springer, London, pp 96-107 
Jun S, Hartwell H, Buhalis D (2012) Impacts of the Internet on travel satisfaction and overall life satisfaction. In: Uysal M, Perdue R, Sirgy MJ (eds) Handbook of tourism and quality-of-life research (Online). Springer Netherlands, Houten, pp 321-337

Kim J, Fesenmaier D, Johnson S (2013) The effect of feedback within social media in tourism experiences. In: Marcus A (ed) Design, user experience, and usability. Web, mobile, and product design [Online]. Springer, Berlin, pp 212-220

Ko CH, Yen JY, Chen CC, Chen SH, Yen CF (2005) Proposed diagnostic criteria of Internet addiction for adolescents. J Nerv Ment Dis 193(11):728-733

Lamsfus C, Martín D, Alzua-Sorzabal A, Torres-Manzanera E (2015) Smart tourism destinations: an extended conception of smart cities focusing on human mobility. In: Tussyadiah I, Inversini A (eds) Information and communication technologies in tourism 2015. Springer International Publishing, London, pp 363-375

Line T, Jain J, Lyons G (2011) The role of ICTs in everyday mobile lives. J Transp Geogr 19(6):1490-1499

Minazzi R, Mauri A (2015) Mobile technologies effects on travel behaviours and experiences: a preliminary analysis. In: Tussyadiah I, Inversini A (eds) Information and communication technologies in tourism 2015. Springer International Publishing, London, pp 507-521

Neuhofer B, Buhalis D, Ladkin A (2014) A typology of technology-enhanced tourism experiences. Int J Tour Res 16(4):340-350

Neuhofer B, Buhalis D, Ladkin A (2015) Technology as a catalyst of change: enablers and barriers of the tourist experience and their consequences. In: Tussyadiah I, Inversini A (eds) Information and communication technologies in tourism 2015. Springer International Publishing, London, pp 789-802

Paris C, Berger E, Rubin S, Casson M (2015) Disconnected and unplugged: experiences of technology induced anxieties and tensions while traveling. In: Tussyadiah I, Inversini A (eds) Information and communication technologies in tourism 2015. Springer International Publishing, London, pp 803-816

Pearce PL (2011) Tourist behaviour and the contemporary world. Channel View, Bristol

Pearce P, Gretzel U (2012) Tourism in technology dead zones: documenting experiential dimensions. Int J Tour Sci 12(2):1-20

Sun ST, Pospisil E, Muslukhov I, Dindar N, Hawkey K, Beznosov K (2013) Investigating users' perspectives of web single sign-on: conceptual gaps and acceptance model. ACM Trans Internet Technol 13(1):2

Tung VWS, Ritchie JRB (2011) Exploring the essence of memorable tourism experiences. Ann Tour Res (Online) 38(4):1367-1386

Tussyadiah I (2014) Expectation of travel experiences with wearable computing devices. In: Zheng X, Tussyadiah I (eds) Information and communication technologies in tourism 2014. Springer International Publishing, London, pp 539-552

Vapen A, Carlsson N, Mahanti A, Shahmehri N (2015) Information sharing and user privacy in the thirdparty identity management landscape (Online). In: Proceedings of the 5th ACM conference on data and application security and privacy_CODASPY'15, San Antonio 02-04 March 2015. ACM, New York, pp 151-153

Wang D, Fesenmaier D (2013) Transforming the travel experience: the use of smartphones for travel. In: Cantoni L, Xiang Z (eds) Information and communication technologies in tourism 2013. Springer, London, pp 58-69

Wang D, Park S, Fesenmaier DR (2012) The role of smartphones in mediating the touristic experience. J Travel Res (Online) 51(4):371-387

Wang D, Xiang Z, Fesenmaier DR (2014) Adapting to the mobile world: a model of smartphone use. Ann Tour Res 48:11-26

White NR, White PB (2007) Home and away. Tourists in a connected world. Ann Tour Res 34(1):88-104

Wu MY, Pearce PL (2016) Tourism blogging motivations: why do chinese tourists create little "lonely planets"? J Travel Res 55(4):537-549

Xiang Z, Gretzel U (2010) Role of social media in online travel information search. Tour Manag (Online) 31(2):179-188

Xiang Z, Magnini VP, Fesenmaier DR (2015) Information technology and consumer behavior in travel and tourism: insights from travel planning using the internet. J Retail Consum Serv (Online), 244-249 